Ambiente \& Água - An Interdisciplinary Journal of Applied Science
ISSN 1980-993X - doi:10.4136/1980-993X
www.ambi-agua.net
E-mail: ambi.agua@gmail.com

\title{
Eficiência de estação de tratamento de esgoto doméstico visando reuso agrícola
}

\author{
doi: 10.4136/ambi-agua.1549
}

Received: 21 Oct. 2014; Accepted: 07 Apr. 2015

\author{
Claudinei Fonseca Souza ; Reinaldo Gaspar Bastos; \\ Marcus Paulo de Moraes Gomes; André Arashiro Pulschen \\ Universidade Federal de São Carlos (UFSCAR), Araras, SP, Brasil \\ Centro de Ciências Agrárias \\ *Autor correspondente: e-mail: cfsouza@cca.ufscar.br, \\ reinaldo@cca.ufscar.br,marcus.ufscar@gmail.com, andrepulschen@hotmail.com
}

\section{RESUMO}

A progressiva demanda por água tem feito do tratamento e reutilização de efluentes um tema de relevância mundial. Considerando tal situação, este trabalho visa monitorar e avaliar a eficiência de uma estação de tratamento de esgoto (ETE) que atua por meio de processos físicos e biológicos mensurando a redução do teor de matéria orgânica do efluente durante o processo de tratamento e a disposição de nutrientes de importância agrícola no efluente tratado. A ETE foi dimensionada para tratar 2500 litros de esgoto por dia e consiste em 04 unidades discriminadas da seguinte forma: tanque séptico, tanque de microalgas, filtro anaeróbio de fluxo ascendente e wetlands com cultivo de Zantedeschia aethiopica L. A eficiência da ETE atingiu, aproximadamente, $90 \%$ na remoção de matéria orgânica proporcionando um efluente adequado para a fertirrigação, mesmo para os elementos $\mathrm{Na}$ e $\mathrm{Ca}$ que tiveram seus teores aumentados devido ao maior acúmulo de matéria orgânica no filtro anaeróbio de fluxo ascendente e wetlands. A ETE apresenta remoção de nitrogênio e fósforo pela ação das microalgas e das macrófitas utilizadas no processo. O efluente final é composto por elementos de importância agrícola tais como nitrogênio, fósforo, cálcio e potássio e, juntamente com a carga de matéria orgânica e sais, enquadra-se, nas determinações da NBR 13.969/1997 (Norma da Associação Brasileira de Normas Técnicas) para reutilização na agricultura, porém sem descartar monitoramentos periódicos da salinidade do solo.

Palavras-chave: anaeróbio, Desmodesmus subspicatus, microalgas, wetlands, Zantedeschia aethiopica $\mathrm{L}$.

\section{Efficiency of domestic wastewater treatment plant for agricultural reuse}

\begin{abstract}
The increasing demand for water has made the treatment and reuse of wastewater a topic of global importance. This work aims to monitor and evaluate the efficiency of a wastewater treatment plant's (WWTP) physical and biological treatment of wastewater by measuring the reduction of organic matter content of the effluent during the treatment and the disposal of nutrients in the treated residue. The WWTP has been designed to treat 2500 liters of
\end{abstract}


wastewater per day in four compartments: a septic tank, a microalgae tank, an upflow anaerobic filter and wetlands with cultivation of Zantedeschia aethiopica L. A plant efficiency of $90 \%$ of organic matter removal was obtained, resulting in a suitable effluent for fertigation, including $\mathrm{Na}$ and $\mathrm{Ca}$ elements that showed high levels due to the accumulation of organic matter in the upflow anaerobic filter and wetlands. The WWTP removes nitrogen and phosphorus by the action of microalgae and macrophytes used in the process. The final effluent includes important agricultural elements such as nitrogen, phosphorus, calcium and potassium and, together with the load of organic matter and salts, meets the determination of NBR 13,969/1997 (Standard of the Brazilian Technical Standards Association) for reuse in agriculture, but periodic monitoring of soil salinity is necessary.

Keywords: anaerobic, Desmodesmus subspicatus, microalgae, wetlands, Zantedeschia aethiopica L.

\section{INTRODUÇÃO}

O desordenamento na gestão e utilização dos recursos hídricos, sejam eles superficiais ou subterrâneos, tornou-se, nos dias atuais, se não o mais preocupante tema de discussões sociais requerendo da comunidade científica e dos órgãos gestores e fiscalizadores, além de soluções, direcionamento técnico e científico para amenização da escassez e todo desequilíbrio que ela acarreta.

Mesmo possuindo grandes mananciais hídricos utilizáveis, nosso país com sua ampla extensão territorial e "generosidade" no que concerne à disposição dos recursos naturais, podem sofrer com a diminuição da oferta de água, principalmente nas regiões com vastas áreas irrigadas e nos grandes centros urbanos como já discorrido por Trentin (2005). Também, na atualidade, o mesmo quadro de risco deve ser citado nas regiões onde as práticas sustentáveis de captação, utilização, reutilização e descarte são ignorados pela população e poder público.

Uma noção desta problemática, discutida por Melo (2011), mostra que a região Nordeste do Brasil que corresponde, aproximadamente, a $30 \%$ da população nacional, possui cobertura de redes de esgotamento sanitário na ordem de $60 \%$ nas áreas urbanas. Não eximindo o fato que, nem sempre tais redes de esgotamento sanitário destinam-se para um sistema ou estação de tratamento de efluentes.

Ainda sobre a questão da escassez, nas localidades que apresentam expressivo adensamento urbano, como a região metropolitana de São Paulo, a oferta de água torna-se cada vez menor e, em alguns casos, sua distribuição entre a população ostenta disparidades beneficiando áreas industriais, comerciais e bairros nobres, fato este que contraria a Constituição de 1988 cujo papel foi, também, de estabelecer a água como bem da União ressaltando que seu aproveitamento deve buscar a mitigação nas desigualdades.

Indubitavelmente, o desregramento da utilização dos recursos hídricos culmina no comprometimento da qualidade da água utilizável, sobretudo, aliado à descontrolada ocupação industrial urbana, à ausência de infraestrutura nas regiões periféricas e também nas zonas rurais onde, em sua maioria, os sistemas de tratamento de água e esgotos são de responsabilidade do próprio usuário que, contraditoriamente, lança seus resíduos para a depuração nos cursos d'água que serão captados para o consumo a jusante, sendo esta última a maior área consumidora de água.

Pela Constituição Nacional Brasileira, a ordem de prioridade do uso da água é estipulada da seguinte forma: consumo humano, industrial e por fim, agricultura; de forma que as águas utilizadas em irrigação serão cada vez mais escassas e de qualidade comprometida.

Para Hespanhol (2003), a substituição de fontes de água é a alternativa plausível para satisfazer as demandas menos restritivas e liberar águas de melhor qualidade para o abastecimento populacional. Esta realidade demanda uma busca de adaptação das atuais 
técnicas de irrigação às condições futuras de escassez de água. A reutilização é uma das alternativas apontadas para o enfrentamento deste problema consagrando-se importante instrumento de gestão ambiental conforme Santos e Mancuso (2003).

Enfatizando os malefícios do despejo dos efluentes, correlacionado ao seu grande potencial em matéria orgânica e outros elementos que nele contém, a utilização destes resíduos pode e deve ser alvo de estudos e práticas que fomentem o reaproveitamento como expressiva possibilidade de economia de recursos.

Considerando este cenário de escassez e desigualdades na oferta dos recursos hídricos, da utilização insustentável e suas consequências danosas; este trabalho possuiu o objetivo de monitorar e avaliar a eficiência da estação piloto de tratamento de esgoto mensurando a redução do teor de matéria orgânica do efluente durante o processo de tratamento e a disposição de nutrientes de importância agrícola no resíduo final, visando o reaproveitamento na agricultura.

\section{MATERIAL E MÉTODOS}

A estação piloto de tratamento de esgoto (ETE) foi instalada na Universidade Federal de São Carlos, no Centro de Ciências Agrárias, localizada na área rural do Município de Araras, Estado de São Paulo nas coordenadas: latitude $22^{\circ} 18 ' 53,23^{\prime \prime}$ Sul e longitude $47^{\circ} 23^{\prime} 00,91$ " Oeste; elevação de $701 \mathrm{~m}$. O clima local, de acordo com a classificação de Köppen é do tipo Cwa (subtropical), com chuvas de verão e com uma precipitação média anual de $1300 \mathrm{~mm}$. O esgoto bruto é proveniente do refeitório e banheiros que são utilizados por funcionários, alunos e visitantes da UFSCar/Araras.

A ETE foi dimensionada para receber, aproximadamente, $2000 \mathrm{~L}$ de esgoto por dia com tempo de detenção hidráulica de 22 horas. Esta estação de tratamento possui várias etapas esperando-se delas a melhor depuração dos resíduos além do aproveitamento dos nutrientes resultantes do processo de tratamento para a fertirrigação.

A ETE foi dividida em quatro unidades, como mostra a Figura 1, sendo: tanque séptico, tanque de microalgas, filtro anaeróbio de fluxo ascendente e wetlands. Todas as unidades são estanques, de material impermeabilizado (polietileno) para que seja evitado qualquer tipo de vazamento e consequente contaminação do solo, lençol freático ou aquífero subterrâneo. Anterior ao tanque séptico foi instalado um caixa de gordura de $24 \mathrm{~L}$.

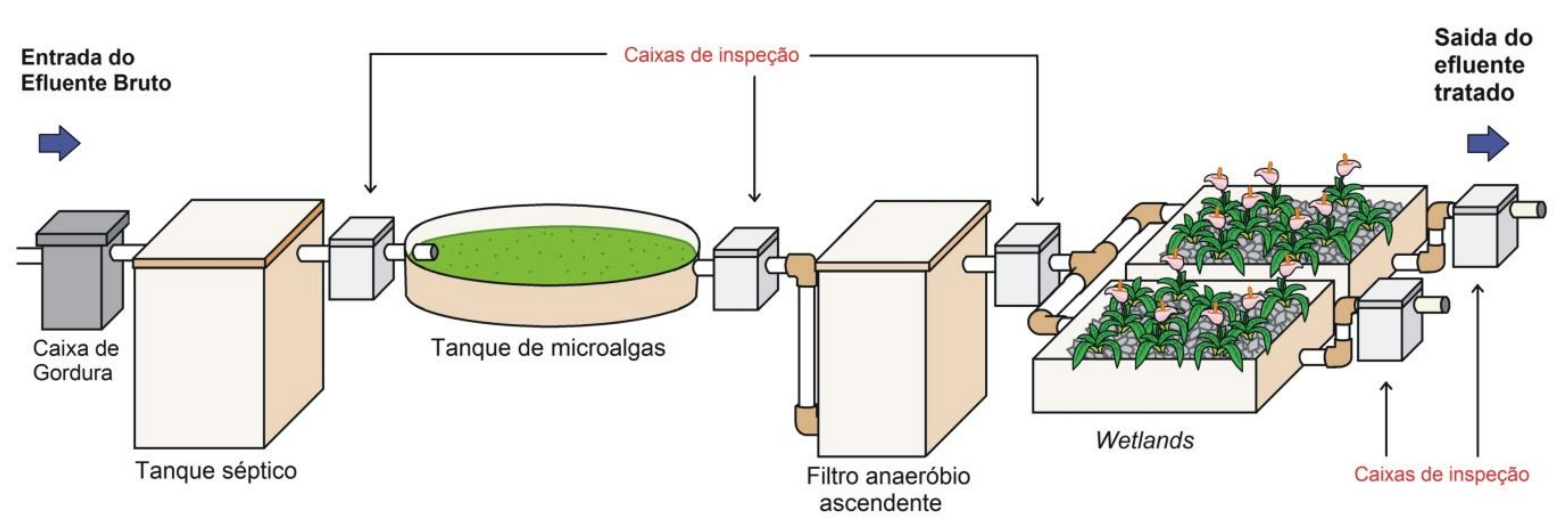

Figura 1. Ilustração esquemática da ETE instalada no Campus Araras da UFSCar.

Fonte: Pulschen et al. (2013).

A ETE usada para obtenção dos dados experimentais foi dimensionada seguindo as seguintes especificações: 
- Caixa de gordura comercial em PVC com capacidade para 24 L, a qual, também, retém material grosseiro através de uma cesta de limpeza na caixa.

- Tanque séptico conforme NBR7229/93 (ABNT, 1993) de volume 5,0 $\mathrm{m}^{3}$ (1,723 m de diâmetro e 2,57 $\mathrm{m}$ de altura).

- Tanque de microalgas de $1 \mathrm{~m}^{3}$ (1,64 m de diâmetro x 0,44 $\mathrm{m}$ de altura), respeitando a profundidade máxima de 1,0 $\mathrm{m}$ para permitir o metabolismo fotossintético com alto tempo de detenção hidráulica (Von Sperling, 1996). O tanque de microalgas foi inoculado a partir de $10,5 \mathrm{~L}$ de suspensão com aproximadamente $10^{6}$ células $\mathrm{mL}^{-1}$ de Desmodesmus subspicatus previamente adaptada ao efluente da universidade.

- Filtro anaeróbio de fluxo ascendente (conforme NBR7229/93) de 2,5 $\mathrm{m}^{3}$ (1,54 m de diâmetro e 1,62 m de altura).

- Wetlands de 2,0 $\mathrm{m}^{3}$. Devido as suas dimensões, a wetland foi dividida em dois tanques com volumes iguais de $1,0 \mathrm{~m}^{3}$ cada e instalados paralelamente $(1,64 \mathrm{~m}$ de diâmetro $\mathrm{x} 0,44 \mathrm{~m}$ de altura para cada tanque). Cultivados com Copos-de-leite (Zantedeschia aethiopica L).

O monitoramento da estação foi realizado através de coletas de amostras nas caixas de inspeção entre as 5 unidades apresentadas na Figura 1, sendo que o primeiro ponto coletado foi esgoto bruto. Para isto, foram utilizados recipientes esterilizados e encaminhados, no mesmo momento, ao Laboratório de Poluição do Solo e Laboratório de Microbiologia Aplicada e Controle da UFSCar para as devidas análises (CETESB, 2011).

Durante o período de 12 meses (maio/2012 até 04/2013) foram realizadas amostragens semanais e a caracterização em termos de DBO (demanda biológica de oxigênio), DQO (demanda química de oxigênio), turbidez, oxigênio dissolvido, condutividade elétrica e potencial hidrogeniônico $(\mathrm{pH})$, totalizando 27 dias de coletas de amostras e 135 amostras analisadas. Também foram feitas quantificações de alguns elementos importantes em termos agrícolas, como nitrogênio total $(\mathrm{N})$, fósforo total $(\mathrm{P})$, potássio $(\mathrm{K})$, sódio $(\mathrm{Na})$ e cálcio $(\mathrm{Ca})$, conforme metodologia da Standard Methods for the Examination of Water and Wastewater (APHA, 2005).

O desempenho da ETE em termo de remoção de compostos das águas residuárias foi avaliado pela DQO, nitrogênio, fósforo e potássio coletados na entrada e saída dos tanques.

A eficiência de remoção destes compostos foi avaliada percentualmente pela diferença na concentração dos substratos considerados na entrada e saída das unidades de tratamento. A biomassa de microalgas cultivadas no tanque foi avaliada pela variação de turbidez do meio reacional em turbidímetro.

A metodologia empregada para a contagem do número mais provável (NMP) de Coliformes termotolerantes (Escherichia coli) seguiu o preconizado por APHA (2005), utilizando-se o método enzimático (sistema Colilert da IDEXX; referência à marca registrada não constitui endosso por parte dos autores). A estimativa de coliformes foi expressa em número mais provável (NMP) em $100 \mathrm{~mL}$ de água.

\section{RESULTADOS E DISCUSSÃO}

A caracterização do efluente bruto foi realizada no período de 22/11/11 até 08/12/11, totalizando 10 amostras, sendo que os resultados são apresentados na Tabela 1 .

De acordo com o monitoramento realizado, pôde-se perceber que os tanques biológicos se adaptaram eficientemente ao efluente da Universidade. O filtro anaeróbio de fluxo ascendente visualmente apresentou, em poucos dias, visualmente uma espessura considerável de biofilme sobre a brita suporte. $\mathrm{O}$ tanque de microalgas foi inoculado majoritariamente com microalgas clorofíceas no dia 03/07/12 e, após 40 dias, apresentou intensa coloração verde, típica deste tipo de sistema. Quanto aos Copos-de-leite (Zantedeschia aethiopica L) nas wetlands, apresentam crescimento vigoroso e florescimento. 
Tabela 1. Caracterização do efluente bruto.

\begin{tabular}{lccc}
\hline \multicolumn{1}{c}{ Parâmetro } & Média & $\begin{array}{c}\text { Máximo } \\
\text { observado }\end{array}$ & $\begin{array}{c}\text { Mínimo } \\
\text { observado }\end{array}$ \\
\hline DQO $\left(\mathrm{mg} \mathrm{L}^{-1}\right)$ & 479,5 & 2044 & 104,4 \\
DBO $\left(\mathrm{mg} \mathrm{L}^{-1}\right)$ & 174,8 & 465 & 68 \\
Nitrogênio total $\left(\mathrm{mg} \mathrm{L}^{-1}\right)$ & 61,9 & 142 & 22 \\
Fósforo total $\left(\mathrm{mg} \mathrm{L}^{-1}\right)$ & 12,6 & 30,3 & 6,2 \\
$\mathrm{pH}$ & 7,4 & 7,8 & 6,1 \\
Condutividade $\left(\mu \mathrm{S} \mathrm{cm}^{-1}\right)$ & 769,5 & 1455 & 222,5 \\
Oxigênio dissolvido $\left(\mathrm{mg} \mathrm{L}^{-1}\right)$ & 2,14 & 5,65 & 0,3 \\
Na $\left(\mathrm{mg} \mathrm{L}^{-1}\right)$ & 21,45 & 58,8 & 8,7 \\
$\mathrm{~K}\left(\mathrm{mg} \mathrm{L}^{-1}\right)$ & 8,44 & 21,5 & 3,1 \\
Ca $\left(\mathrm{mg} \mathrm{L}^{-1}\right)$ & 11,35 & 29,8 & 2,4 \\
Turbidez (NTU) & 173,2 & 443 & 32,7 \\
Coliformes totais $\left(\mathrm{NMP} 100 \mathrm{~mL}^{-1}\right)$ & $3,1 \times 10^{8}$ & $1,0 \times 10^{9}$ & $2,1 \times 10^{6}$ \\
E. coli $\left(\mathrm{NMP} 100 \mathrm{~mL}^{-1}\right)$ & $2,6 \times 10^{6}$ & $1,4 \times 10^{8}$ & $2 \times 10^{5}$ \\
\hline
\end{tabular}

Devido ao grande número de amostras analisadas, a eficiência geral da estação foi disposta na Tabela 2, utilizando-se a média dos dias analisados para todos os parâmetros, considerando os valores médios de entrada e saída neste período, sendo a entrada esgoto bruto e saída após as wetlands. O experimento demonstra resultados de redução de DQO e DBO na ordem de $94,8 \%$ e $93,3 \%$, apresentando valores médios de $30,52 \mathrm{mg} \mathrm{L}^{-1}$ e $11,63 \mathrm{mg} \mathrm{L}^{-1}$ na saída, respectivamente. Os valores adquiridos para os parâmetros DQO e DBO respeitam o Artigo 18 do Decreto $\mathrm{n}^{\circ}$ 8.468/76 (São Paulo, 1976) que estipula $60 \mathrm{mg} \mathrm{L}^{-1}$ de matéria orgânica no efluente. A maior remoção de DBO ocorreu no dia 04/07/12, atingindo eficiência de $97,3 \%$.

Segundo Hespanhol (2003), valores de DBO inferiores a $100 \mathrm{mg} \mathrm{L}^{-1}$ não afetam a absorção de água pelas raízes das plantas. Porém, USEPA (2004) recomenda que os valores de DBO não devam ser superiores a $30 \mathrm{mg} \mathrm{L}^{-1}$ para irrigação de culturas consumidas cozidas e $10 \mathrm{mg} \mathrm{L}^{-1}$ para plantas consumidas cruas, estando portanto o efluente muito próximo do adequado inclusive para culturas de consumo cru.

A estação apresentou redução de mais de $95 \%$ da turbidez do efluente, sendo que esse parâmetro não sofreu redução gradativa, variando muito nas diferentes unidades de tratamento. Um exemplo deste fato é o aumento da turbidez na saída do tanque de microalgas devido à intensa coloração esverdeada proveniente da proliferação da flora microbiológica (Figura 2).

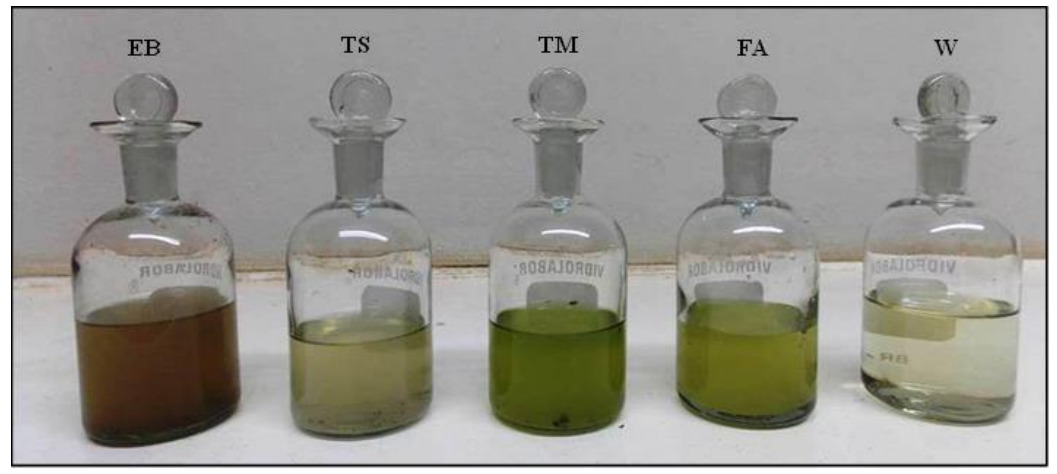

Figura 2. Mudanças de turbidez. EB: Esgoto Bruto; TS: Tanque Séptico; TM: Tanque de Microalgas; FA = Filtro Anaeróbio e $\mathrm{W}=$ Wetlands. 
Tabela 2. Parâmetros de eficiência da estação, em relação à média dos valores de entrada (esgoto bruto) e saída (último ponto de coleta).

\begin{tabular}{lccccc}
\hline Parâmetros & Entrada & $\begin{array}{c}\text { Coeficiente de } \\
\text { Variação }\end{array}$ & Saída & $\begin{array}{c}\text { Coeficiente de } \\
\text { Variação }\end{array}$ & $\begin{array}{c}\text { Eficiência } \\
(\%)\end{array}$ \\
\hline OD $\left(\mathrm{mg} \mathrm{L}^{-1}\right)$ & 1,80 & $\pm 1,52$ & 2,35 & $\pm 0,98$ & 131 \\
pH & 6,95 & $\pm 1,23$ & 7,36 & $\pm 0,52$ & 06 \\
CE $\left(\mu \mathrm{S} \mathrm{cm}^{-1}\right)$ & 465,55 & $\pm 219,97$ & 634,64 & $\pm 193,80$ & $36^{*}$ \\
Turbidez $(\mathrm{NTU})$ & 240,67 & $\pm 167,01$ & 11,91 & $\pm 31,55$ & 95 \\
Na $\left(\mathrm{mg} \mathrm{L}^{-1}\right)$ & 28,24 & $\pm 21,89$ & 68,85 & $\pm 28,74$ & $144^{*}$ \\
K $\left(\mathrm{mg} \mathrm{L}^{-1}\right)$ & 10,89 & $\pm 7,99$ & 11,96 & $\pm 3,57$ & $10^{*}$ \\
Ca $\left(\mathrm{mg} \mathrm{L}^{-1}\right)$ & 13,62 & $\pm 9,72$ & 16,70 & $\pm 8,56$ & $23^{*}$ \\
NT $\left(\mathrm{mg} \mathrm{L}^{-1}\right)$ & 113,11 & $\pm 39,34$ & 77,65 & $\pm 33,46$ & 31 \\
PT $\left(\mathrm{mg} \mathrm{L}^{-1}\right)$ & 66,00 & $\pm 70,00$ & 14,00 & $\pm 0,80$ & 79 \\
CT NMP 100mL & $1,49.10^{-1}$ & Não se aplica & $1,16.10^{6}$ & Não se aplica & 99 \\
E. coli NMP $100 \mathrm{~mL}^{-1}$ & $2,26.10^{6}$ & Não se aplica & $8.10^{4}$ & Não se aplica & 96 \\
DQO $\left(\mathrm{mg} \mathrm{L}^{-1}\right)$ & 587,34 & $\pm 430,43$ & 30,52 & $\pm 25,64$ & 95 \\
\hline
\end{tabular}

OD: oxigênio dissolvido; CE: condutividade elétrica; Na: sódio; K: potássio; Ca: cálcio; NT: nitrogênio total Kjeldhal; PT: fósforo total; CT: coliformes totais; NMP: número mais provável.

*Resultados considerados ineficientes.

A ETE também exibiu redução de coliformes totais $(99,2 \%)$ e E. coli $(96,4 \%)$. Todavia, em todas as análises realizadas desde o dia 12/07/12, a concentração de coliformes totais ficou abaixo do limite de detecção das diluições empregadas $\left(<10^{3}\right.$ células $\left.\mathrm{mL}^{-1}\right)$, sugerindo que a eficiência pode ser ainda maior. Em alguns dias, como 04/07/12 e 16/08/12, a remoção chegou a valores acima de $98,6 \%$ e $99,3 \%$ de E. coli, sendo os dias com maior eficiência da estação para este parâmetro.

De acordo com o Decreto $\mathrm{n}^{\circ} 8.468 / 76$, art. 18, os valores máximos de coliformes termotolerantes, onde se enquadra a E. coli, são de $100 \mathrm{NMP} 100 \mathrm{~mL}^{-1} \mathrm{e}$ de 5.000 NMP $100 \mathrm{~mL}^{-1}$ para coliformes totais, sendo que esses valores não foram observados em nenhum dos dias do tratamento. Todavia, deve-se considerar a alta concentração de coliformes presentes no efluente inicial $\left(3,22 \times 10^{8} \mathrm{NMP} 100 \mathrm{~mL}^{-1}\right.$ e $2,62 \times 10^{7} \mathrm{NMP} 100 \mathrm{~mL}^{-1}$, respectivamente), o que dificulta a redução para os parâmetros exigidos pelo decreto e indica a necessidade de tratamento terciário para a utilização do sistema em comunidades rurais e isoladas.

Quanto ao $\mathrm{pH}$, este teve uma discreta alteração entre as unidades da ETE que varia de 7,4 a 6,9 e de acordo com o Artigo 18 do Decreto $\mathrm{n}^{\circ}$ 8.468/76, o $\mathrm{pH}$ deve ficar entre os valores de 5 e 9 . O oxigênio dissolvido teve eficiência de $31 \%$ partindo de $1,80 \mathrm{mg} \mathrm{L}^{-1}$ na entrada para $2,35 \mathrm{mg} \mathrm{L}^{-1}$ na saída da estação. Esse aumento de oxigênio dissolvido é atribuído à atuação do tanque de microalgas e wetlands onde o metabolismo predominante é a fotossíntese. Cabe ressaltar que estes valores apresentam-se adequados ao uso na agricultura.

Em relação à condutividade elétrica, pôde-se observar o aumento de $36,3 \%$ em relação ao inicio da estação. Esse aumento na condutividade elétrica reflete o acúmulo de cálcio, sódio e potássio nos estágios que contém brita na estação. O sódio apresentou um aumento de 28,24 para $68,85 \mathrm{mg} \mathrm{L}^{-1}$ (cerca de $143,7 \%$ ), sendo o cátion que mais aumentou em concentração. $\mathrm{O}$ cálcio aumentou $23 \%$ e o potássio $10 \%$. A elevação dos valores desses cátions é atribuída ao 
acúmulo do efluente nos estágios com brita e, também, pelo aumento do tempo de retenção hidráulica. Corroborando, o ocorrido no estudo desenvolvido no Município de Braço do Norte/SC por Araújo et al. (2012), que mostra seu estágio denominado "filtro de pedra" como acumulador de matéria orgânica e, consequentemente, elementos que nela contém.

Segundo Almeida (2010), o intervalo usual de condutividade em águas de irrigação varia de $0-3000 \mu \mathrm{S} \mathrm{cm}^{-1}$, porém, também ressalta que elevadas concentrações salinas podem trazer prejuízo ao cultivar e solo, caso a irrigação seja feita de modo inadequado, também observado por Cerqueira et al. (2008).

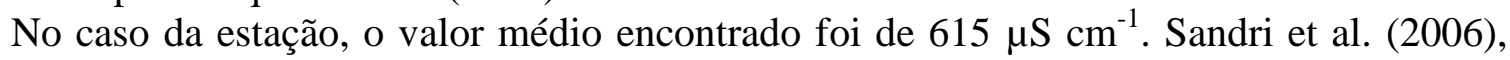
em seu trabalho, utilizou água de reúso para irrigação da alface, com valores de condutividade entre $520 \mu \mathrm{S} \mathrm{cm}^{-1}$ e $630 \mu \mathrm{S} \mathrm{cm} \mathrm{cm}^{-1}$. Usando como classificação os parâmetros propostos por Ayers e Westcot (1999), a água utilizada possuía salinidade sem nenhum grau de restrição em que a condutividade pode chegar até $700 \mu \mathrm{S} \mathrm{cm}$, podendo ser utilizada na irrigação sem nenhum problema, até mesmo para culturas mais sensíveis à salinidade. De acordo com esses parâmetros, o efluente estaria adequado para o reúso, porém essa classificação não considera os efeitos sobre o solo.

A análise individual das unidades da ETE pode ser verificada na Tabela 3. Por se tratar de uma estação com diferentes unidades de tratamento, cada estágio apresenta uma função específica e a eficiência de cada um deles foi analisada de acordo com sua capacidade de alteração nos parâmetros DQO, turbidez, oxigênio dissolvido, condutividade elétrica, $\mathrm{Na}, \mathrm{N}$, $\mathrm{P}, \mathrm{K}, \mathrm{Ca}$, coliformes totais e $E$. coli em relação ao efluente de entrada no respectivo filtro. Sendo assim, para o tanque séptico e caixa de gordura, o efluente de entrada é o próprio efluente bruto da universidade, para o tanque de microalgas, o efluente de entrada é o efluente da saída do tanque séptico e assim subsequentemente.

A primeira porção da estação a ser analisada consiste do sistema de caixa de gordura e tanque séptico, o qual apresentou redução de $76,65 \%$ da DQO, $80,88 \%$ da turbidez $(80,88 \%)$ e quase um ciclo logaritmo na quantidade de coliformes totais $(86,76 \%)$ e E. coli $(80,99 \%)$, destacando em termos de eficiência para os parâmetros microbiológicos. Não obstante, neste tanque também se observou o aumento da condutividade $(49,00 \%)$, de $\mathrm{Na}(29,52 \%)$, $\mathrm{K}$ $(45,12 \%)$ e $\mathrm{Ca}(13,58 \%)$.

Tanto a redução na DQO, turbidez, coliformes totais, E. coli, como o aumento dos valores de condutividade e os cátions podem ser justificados, também, pelo grande volume útil do tanque séptico $(5.000 \mathrm{~L})$, o qual equaliza todo o efluente recebido para os tanques seguintes, além de reter a água por mais tempo em seu interior. Desta forma, devido ao maior tempo de retenção, ocorreu uma maior depuração de matéria orgânica e remoção de patógenos.

A caixa de gordura, a qual possui um pequeno sistema de gradeamento, também ajuda a reter parte dos sólidos presentes no efluente, além de remover óleos. Esta passa por limpezas semanais e sempre que excede seu potencial de armazenamento (24 L).

$\mathrm{O}$ fato de o tanque séptico equalizar o efluente também pode ter colaborado para o aumento da condutividade e dos cátions presentes, pois durante o primeiro período de caracterização do efluente (22/11/2011 até o dia 08/12/2011), onde as amostras eram normalmente coletadas entre 12:00 e 13:00 horas foram observados valores de condutividade de até $1455 \mu \mathrm{S} \mathrm{cm}^{-1}, 134 \mathrm{mg} \mathrm{L}^{-1}$ de Na, 43,9 $\mathrm{mg} \mathrm{L}^{-1}$ de Ca e 52,6 $\mathrm{mg} \mathrm{L}^{-1}$ de $\mathrm{K}$, muito superiores aos valores observados durante o período de monitoramento da estação, a qual é realizado predominantemente no período da manhã, entre $8 \mathrm{~h} 30$ e $9 \mathrm{~h} 30$.

Sendo assim, as características físico-químicas do efluente variam de acordo com a hora do dia, sendo que em certos momentos, os valores de cátions presentes no efluente estão elevados. 
Tabela 3. Eficiência individual nas diferentes unidades de tratamento do esgoto.

\begin{tabular}{lcccc}
\hline \multicolumn{1}{c}{ Parâmetro } & $\begin{array}{c}\text { Caixa de gordura e } \\
\text { Tanque séptico }\end{array}$ & $\begin{array}{c}\text { Tanque de } \\
\text { microalgas }\end{array}$ & $\begin{array}{c}\text { Filtro } \\
\text { anaeróbio }\end{array}$ & Wetland \\
\cline { 2 - 5 } DQO & 76,65 & 5,18 & 38,63 & 61,75 \\
Turbidez & 80,88 & NA & 36,35 & 65,34 \\
OD & NA & 124,42 & NA & NA \\
Condutividade elétrica & NA & 12,64 & NA & 6,30 \\
Na & NA & 0,68 & NA & NA \\
K & NA & 4,97 & 10,76 & 10,71 \\
Ca & NA & NA & NA & 1,20 \\
Coliformes totais & 86,76 & NA & 84,18 & 63,98 \\
E. coli & 80,99 & NA & 75,69 & 31,03 \\
NT & -- & 33,55 & -- & 0,75 \\
PT & -- & 81,16 & -- & 30,38 \\
\hline
\end{tabular}

Nota: NA - Não Alterada.

Em relação ao tanque de microalgas, este apenas recebeu o inoculo no dia 03/07/12, sendo que anteriormente apresentou-se como um simples tanque aberto. Apesar da justificativa deste tanque na remoção de nitrogênio e fósforo, houve uma discreta remoção de DQO $(5,18 \%)$ e aumento na turbidez $(17,37 \%)$ devido ao desenvolvimento dos micro-organismos fotossintetizantes. Pela sua particularidade, este foi o único tanque da estação com este efeito. Além disso, também por conta do metabolismo fotossintético, houve um aumento do oxigênio dissolvido no efluente na ordem de $124,42 \%$, além de ter sido o único a diminuir discretamente a condutividade elétrica $(12,64 \%)$, provavelmente devido ao consumo de sais. Em termos de nutrientes, verificou-se a redução do nitrogênio total em $33,55 \%$ e fósforo total em $81,16 \%$.

$\mathrm{Na}$ sequência da estação piloto, o filtro anaeróbio de fluxo ascendente apresentou um aumento da quantidade de $\mathrm{Na}(73,16 \%)$ e, consequentemente, na condutividade elétrica $(11,77 \%)$. A elevação dos valores desses cátions é atribuída ao acúmulo do efluente nos estágios com brita e, também, pelo aumento do tempo de retenção hidráulica corroborando o ocorrido no estudo desenvolvido no Município de Braço do Norte/SC por Araújo et al. (2012), que mostra seu estágio denominado "filtro de pedra" como acumulador de matéria orgânica e, consequentemente, elementos que nela contém.

Por fim, na wetland ocorre redução de DQO (61,75\%), sendo a maior redução desse parâmetro em toda a estação depois do tanque séptico. Possui redução da turbidez na ordem de $65,34 \%$, colaborando para gerar um efluente mais polido ao final do processo. Este estágio contribui com remoção de coliformes totais $(63,98 \%)$ e diminuição de E. coli $(31,03 \%)$.

A eficiência desta etapa em relação aos demais pode estar relacionada à natureza do efluente que ele recebe. Por já ter passado por três outros diferentes sistemas, o efluente pode apresentar uma composição mais biodegradável, facilitando o trabalho da wetland. Todavia, Ribas e Fortes Neto (2006) demonstraram em seu trabalho a eficiência de sistemas de leitos cultivados, ou wetlands, com Copos-de-leite, no qual obteve reduções de DQO, coliformes totais e $E$. coli, mesmo em efluentes sem pré-tratamento.

Assim como já discutido anteriormente, na caracterização realizada entre os dias 22/11/11 até o dia 08/12/11, em que as amostras eram coletadas em horários diferentes das coletas realizadas no monitoramento da estação, a média da DQO foi de $466 \mathrm{mg} \mathrm{L}^{-1}$, sendo 
que a média encontrada durante o monitoramento foi de $605 \mathrm{mg} \mathrm{L}^{-1}$. Isso demonstra que em certos períodos do dia, o efluente pode estar pouco carregado de matéria orgânica, diluindo o efluente no interior do tanque séptico. Além disso, foi observado que os períodos de maior intensidade de DQO no efluente ocorrem no início do período letivo ( 8 h00 - 8h30), após o almoço $(12 \mathrm{~h} 00-14 \mathrm{~h} 00)$ e no início do período letivo noturno (18h00), sendo que no restante dos horários, o efluente possui uma carga menor de DQO, o que resulta em diluição no interior do tanque séptico. O mesmo poderia ocorrer para os coliformes.

Tendo em vista esses valores, o efluente estaria adequado para o reuso na agricultura. Contudo, mesmo com a redução da quantidade de coliformes pelo sistema de tratamento, este ainda possui valores elevados. Desta forma, a irrigação por gotejamento seria o processo mais indicado, o qual já vem sendo adotado nos experimentos em casa de vegetação na Universidade, sendo inviável a irrigação por aspersão. Por outro lado, o efluente poderia ser utilizado desde que passasse por um tratamento terciário de desinfecção através de hipoclorito de sódio ou radiação ultravioleta.

Em relação à condutividade, esta se apresentou elevada e aumentou após passar pelo sistema de tratamento montado na Universidade. Sousa et al. (2005) utilizou em seus experimentos água de reuso para a cultura do pimentão, obtendo resultados promissores em termos de produção. Porém, os efluentes utilizados possuíam condutividade entre $1.500 \mu \mathrm{S} \mathrm{cm}^{-1}$ e $1.600 \mu \mathrm{S} \mathrm{cm}^{-1}$, valores mais elevados do que aqueles encontrados na estação da universidade. O mesmo ocorreu com o trabalho de Lucena et al. (2006), no qual os valores de condutividade de água de reuso era de $1.360 \mu \mathrm{S} \mathrm{cm}^{-1}$. Talvez pelo fato dos experimentos não terem se estendido por longos períodos, os autores não observaram mudanças no solo após a aplicação da água de reuso, como observado por Cerqueira et al. (2008).

Logo, de acordo com os padrões analisados, o efluente tratado pela estação pode ser utilizado para aplicação na agricultura, desde que não se utilize a técnica de aspersão e, também, se monitore a salinidade do solo.

\section{CONCLUSÕES}

Nas condições experimentais pôde-se concluir que a ETE apresenta ser eficiente na capacidade de depuração de matéria orgânica e nutrientes.

O efluente final é composto por elementos de importância agrícola tais como nitrogênio, fósforo, cálcio e potássio e, juntamente com a carga de matéria orgânica e sais, enquadra-se, nas determinações da NBR 13.969/1997 (ABNT, 1997) para reutilização na agricultura.

Apesar da eficácia da ETE na remoção de matéria orgânica e da capacidade de remoção de coliformes totais e E. coli, observa-se a necessidade de tratamento terciário para remoção de patógenos, porém sem descartar monitoramentos periódicos da salinidade do solo.

\section{REFERÊNCIAS}

ALMEIDA, O. A. Qualidade da água de irrigação. Cruz das Almas: Embrapa Mandioca e Fruticultura, 2010. 227p.

AMERICAN PUBLIC HEALTH ASSOCIATION - APHA. Standards Methods for the Examination of Water and Wastewater. 21th ed. Washington, DC, 2005.

ARAÚJO, I. S.; OLIVEIRA, J. R. L.; ALVES, R. G. C. M.; BELLI FILHO, P.; COSTA, R. H. R. Avaliação de sistema de tratamento de dejetos suínos instalado no Estado de Santa Catarina. Revista Brasileira de Engenharia Agrícola e Ambiental, Campina Grande, v. 16, n. 7, p. 745-753, 2012. http://dx.doi.org/10.1590/S141543662012000700007 
ASSOCIAÇÃO BRASILEIRA DE NORMAS TÉCNICAS - ABNT. NBR-7229: projeto, construção e operação de sistemas de tanques sépticos: procedimento. Rio de Janeiro, 1993.

ASSOCIAÇÃO BRASILEIRA DE NORMAS TÉCNICAS - ABNT. NBR-13969: Tanques sépticos - Unidades de tratamento complementar e disposição final dos efluentes líquidos - Projeto, construção e operação. Rio de Janeiro, 1997.

AYERS, R. S.; WESTCOT, D. W. A qualidade de água na agricultura. 2. ed. Campina Grande: UFPB, 1999. 153 p. (FAO - Estudos Irrigação e Drenagem, 29).

CERQUEIRA; L. L.; FADIGAS, F. S.; PEREIRA, F. A.; GLOAGUEN, T. V.; COSTA, J. A. desenvolvimento de Heliconia psittacorum e Gladiolus hortulanus irrigados com águas residuárias tratadas. Revista Brasileira de Engenharia Agrícola e Ambiental, Campina Grande, v. 12, n. 6, p.606-613, 2008. http://dx.doi.org/10.1590/s141543662008000600006

COMPANHIA DE TECNOLOGIA AMBIENTAL DO ESTADO DE SÃO PAULO CETESB. Guia nacional de coleta e preservação de amostras: água, sedimento, comunidades aquáticas e efluentes líquidos. São Paulo, 2011.

HESPANHOL, I. Potencial de reúso de água no Brasil: agricultura, indústria e recarga de aquíferos. In: MANCUSO, P. C. S.; SANTOS, H. F. Reúso de água. Barueri: Manole, 2003. p.37-96.

LUCENA, A. M.; AlmeIDA, F. A. C.; COSTA, F. X.; GUERRA, H. O. C. Emprego de substratos irrigados com água de abastecimento e residuária na propagação do flamboyant. Revista de Biologia e Ciências da Terra, Campina Grande, v. 6, n. 1, p. 115-121, 2006.

MELO, A. A. O uso de água residuária e composto orgânico no cultivo do algodão a partir de uma visão socioambiental. 2011. 90f. Dissertação (Mestrado em Engenharia Agrícola) - Universidade Federal de Campina Grande, Campina Grande, 2011.

PUlSCHEN, A. A.; GOMES, M. P. M.; BASTOS, R. G.; SOUZA, C. F. Tratamento biológico de efluentes sanitários em ETE mista. In: SIMPÓSIO INTERNACIONAL SOBRE GERENCIAMENTO DE RESÍDUOS AGROPECUÁRIOS E AGROINDUSTRIAIS, 3., 2013, São Pedro. Anais... São Paulo: SIGERA, 2013.

RIBAS, T. B. C.; FORTES NETO, P. Avaliação do desempenho da estação de tratamento de esgoto compacta por leito de raízes implantada no município de Jacareí/SP. In: CONGRESSO DE SAÚDE E QUALIDADE DE VIDA DO CONE LESTE PAUliSTA, 2006, São José dos Campos. Anais... São José dos Campos: UNIVAP, 2006.

SANDRI, D.; MATSURA, E. E.; TESTEZLAF, R. Teores de nutrientes na alface irrigada com água residuária aplicada por sistemas de irrigação. Engenharia Agrícola, Jaboticabal, v. 26, n. 1, p. 45-57, 2006. http://dx.doi.org/10.1590/S010069162006000100006

SANTOS, H. F.; MANCUSO, P. C. S. A escassez e o reúso de água em âmbito mundial. In: MANCUSO, P. C. S.; SANTOS, H. F. Reúso de Água. Barueri: Manole, 2003. p. 21 36. 
SÃO PAULO (Estado). Decreto no 8468. Aprova o Regulamento da Lei $n^{\circ}$ 997, de 31 de maio de 1976, que dispõe sobre a prevenção e o controle da poluição do meio ambiente. São Paulo,1976.

SOUSA, J. T.; CEBALlOS, B. S. O.; HENRIQUE, I. N.; DANTAS, J. P.; LIMA, S. M. S. Reúso de água residuária na produção de pimentão (Capsicum annuum L.). Revista Brasileira de Engenharia Agrícola e Ambiental, Campina Grande, v. 10, n. 1, p. 8996, 2005. http://dx.doi.org/10.1590/S1415-43662006000100014

TRENTIN, C.V. Diagnóstico voltado ao planejamento do uso de águas residuárias para irrigação, nos cinturões verdes da região metropolitana de Curitiba-PR. 2005. 112f. Dissertação (Mestrado em Ciência do Solo) - Universidade Federal do Paraná, Curitiba, 2005.

UNITED STATES. Environmental Protection Agency (USEPA). Guidelines for water reuse. Washington, 2004.

VON SPERLING, M. Princípios básicos do tratamento de esgotos - Princípios do tratamento biológico de águas residuárias. Belo Horizonte: UFMG, 1996. 211p. 